\title{
DETERMINATION OF THE MAGNETIC INDUCTION IN SHEET STEEL
}

\author{
By Raymond L. Sanford and James M. Barry
}

\section{ABSTRACT}

For the past 15 years the Burrows permeameter has been accepted in the United States as the standard method for the magnetic testing of sheet steel. The Fahy Simplex permeameter, however, offers some advantages in the way of simplicity and convenience of operation. The accuracy of the latter instrument for this type of material has been somewhat in doubt and an intercomparison extending over a period of four years failed to give conclusive results. The investigation here reported was undertaken to discover the cause of discrepancies between the two methods, to decide which, if either, is preferable and to determine the conditions under which the best results can be obtained. The results of the investigation show that the differences are to be attributed mainly to lack of uniformity in the material rather than to errors inherent in either method and that the Simplex permeameter is less sensative to this than the Burrows. The test samples should consist of not more than 15 strips preferably 10 , and should be not less than $3 \mathrm{~cm}$ wide.

\section{CONTENTS}

I. Introduction

II. Description of test methods .

1. Burrows permeameter

2. Fahy Simplex permeameter. 730

III. Results......... 730

1. Effect of uniformity of the specimen ...... 730

2. Effect of width of the specimen . .

3. Effect of number of strips . .

4. Hysteresis measurements _... 740

IV. Conclusions........... 741

\section{INTRODUCTION}

The importance of commercial magnetic testing is continually increasing. It has been estimated that in 1925 approximately $\$ 10,000,000$ worth of material was purchased on the basis of specifications as to magnetic properties, a substantial part of which was in the form of sheets to be used in the cores of various types of electrical apparatus and machinery. Two types of test are ordinarily made on sheet steel. One is for the determination of the power loss in a unit quantity of the material when subjected to the influence of an alter- 
nating magnetizing current. This is known as core loss. The other test is a determination of values of normal magnetic induction resulting from the application of given values of magnetizing force. The core-loss test is very well standardized, and there is only one method in general use. The normal induction test, on the other hand, is not so well standardized. In 1911 the American Society for Testing Materials adopted a specification entitled "Standard Methods of Test for Magnetic Properties of Iron and Steel " ${ }^{1}$ in which a special arrangement of the Burrows compensated-double-yoke method was specified. This method continued to be the only one approved by the A. S. T. M. until the year 1924 when the specification was revised to permit the use of any permeameter having a certain required accuracy. Some time prior to this, the Fahy Simplex permeameter began to be used. This instrument continued to grow in favor due to its relative simplicity and convenience of operation, but there was some uncertainty as to its applicability for the testing of sheet steel. The A. S. T. M. specification of 1924 provides that the accuracy of any permeameter shall be determined by means of standardized specimens tested by certain specified methods. The only one of the specified standardizing methods suitable for samples of sheet steel is the Burrows permeameter. One of the prime requisites for such a standardization is a specimen magnetically homogeneous along its length. The preparation of a sample of sheet steel having the requisite degree of uniformity is attended with some difficulty because the magnetic permeability shows rather large variations. It is not uncommon, for instance, to find variations as great as 20 per cent in different parts of the same sheet. For this reason the Bureau of Standards has been running an intercomparison of the Burrows permeameter and the Fahy Simplex permeameter using as test specimens samples of materials which were submitted for test. The results of this intercomparison, which extended over a period of approximately four years, may be summarized briefly as follows: In about 30 per cent of the tests the results with the two permeameters agreed well within the allowable experimental error; in 60 per cent of the tests the normal induction values obtained by the Simplex permeameter were higher than those given by the Burrows apparatus, while in the remaining 10 per cent the Simplex gave lower values than the Burrows. In riew of the importance of the problem and the inconclusive nature of the results of the intercomparison just referred to, it was felt that a systematic investigation should be undertaken in order to find out the sources of discrepancy and the conditions under which a satisfactory degree of accuracy can be obtained. The results of this investigation are here presented.

3 A. S. T. M. Year Book; 1911. 


\section{DESCRIPTION OF TEST METHODS}

Although a detailed description of the theory and operation of the two permeameters under investigation is not necessary, a brief outline of their underlying principles will aid in the discussion of the experimental results.

\section{BURROWS PERMEAMETER}

The Burrows permeameter has a magnetic circuit in which the magnetomotive force is so distributed as to reduce the magnetic leakage to a minimum.

Figure 1 shows the magnetic circuit and the relative position of the magnetizing and test coils. The test specimen and its auxiliary, which should be of the same size and material, are joined at the ends by soft iron yokes which make good magnetic joints and complete the magnetic circuit. The magnetizing coils $T$ and $A$ are located

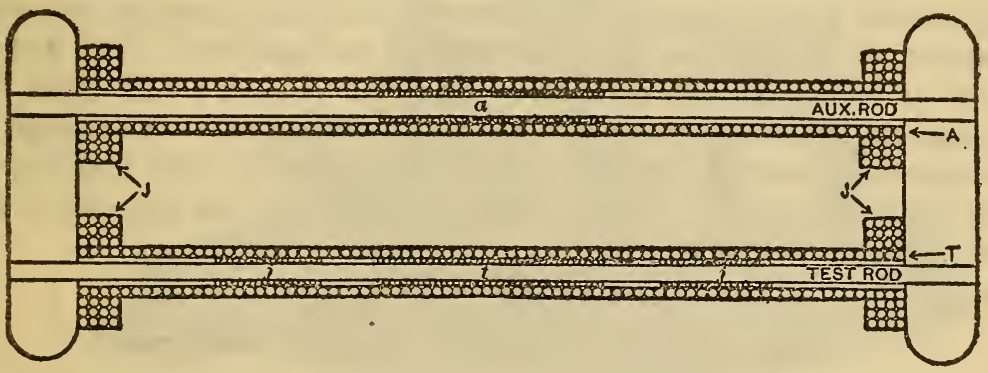

Fig. 1.-Magnetic circuit of the Burrows permeameter

over the test rod and auxiliary, respectively. Coil $J$ is in four sections, connected in series, and located over the ends of the rods as near to the joints as possible. In operation the currents in these three windings are so adjusted before each reading that there is equal flux in the two rods and no leakage from the greater part of the test rod. When this condition is realized, the value of the applied magnetizing force can be calculated from the current and number of turns per centimeter in the solenoid surrounding the test rod. For testing the compensation and determining the value of the induction when the compensation is properly adjusted, there are three test coils designated as $t, a$, and $j$, respectively. These coils are each of the same number of turns and are distributed as shown in the figure; $t$ is wound over the middle of the test bar, $a$ over the middle of the auxiliary bar, and $j$ is wound half over one end and half over the other end of the test bar far enough away from the yokes and joints to avoid disturbances from these causes. When, upon reversal of the current in the magnetizing windings, there is no residual deflection in the ballistic galvanometer whether connected to $t$ and $a$ or 
to $t$ and $j$ in series opposition, the magnetizing currents are properly adjusted. Under these conditions the induction is measured in terms of the deflection of the ballistic galvanometer connected to $t$ alone and the magnetizing force is proportional to the current in the winding $T$.

\section{FAHY SIMPLEX PERMEAMETER}

This permeameter (fig. 2) operates on a somewhat different principle from that of the Burrows apparatus and requires but a single specimen. The magnetizing force is applied by means of an electromagnet, across the poles of which the specimen is clamped. A uniformly wound test coil extends over the whole length of the specimen. A ballistic galvanometer connected to this test coil indicates the induction in the specimen when the magnetizing current is reversed.

The magnetizing force is measured by means of a test coil uniformly wound on a nonmagnetic form and extending between two iron blocks which are clamped to the ends of the specimen. The deflection of a ballistic galvanometer connected to such a coil when the magnetizing force is changed in value is proportional to the change in magnetic potential between the ends of the coil. The function of the iron blocks is in effect to transfer the ends of the test coil to the ends of the specimen.

\section{RESULTS}

\section{EFFECT OF UNIFORMITY OF THE SPECIMEN}

One of the most striking examples of the results obtained in the intercomparison mentioned above is shown in the curves of Figures 3 and 4. The two samples tested were from the same source and of very nearly the same quality. In the test represented by Figure 3 the differences are large, the magnetizing force corresponding to a given induction as determined by the two methods differing by as much as 30 per cent in the neighborhood of maximum permeability. In the test illustrated in Figure 4, on the other hand, the agreement is surprisingly good considering the radical difference in the two methods. The obvious conclusion from these results is that the difference in the order of agreement must be attributed to peculiarities in the sample themselves rather than to errors inherent in either testing method. For this reason an attempt was made to discover wherein the difference between the two specimens lay.

In a previous investigation ${ }^{2}$ it was found that the results of normal induction tests made with the Burrows permeameter were greatly affected by a lack of magnetic uniformity along the length of the specimen and it was suspected that the main difference between 
Scientific Papers of the Bureau of Standards, Vol. 21

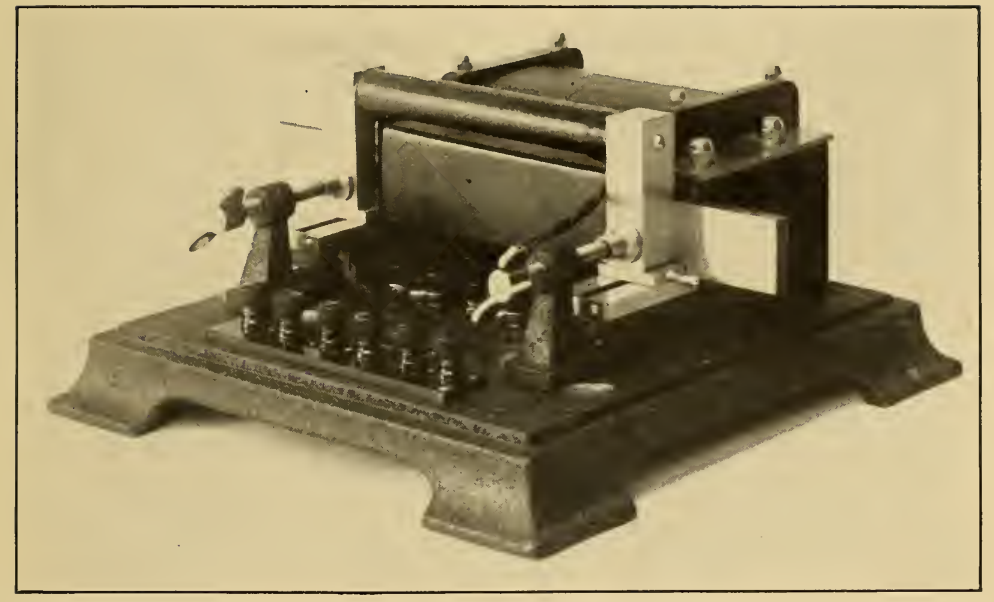

FIG. 2.-The Fahy Simplex permeameter 
the two specimens lay in the degree of their magnetic uniformity. An attempt was made to determine the variations; but satisfactory results were not obtained, because the samples were too short. It was

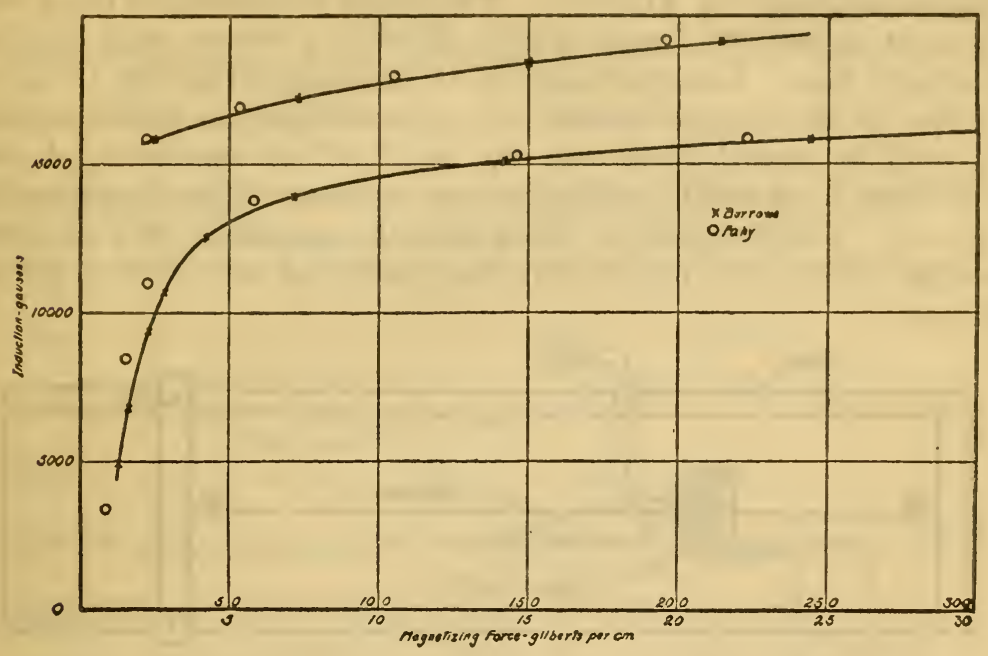

FIG. 3.-Normal induction curve showing poor agreement between the Burrows permeameter and the Fahy Simplex permeameter

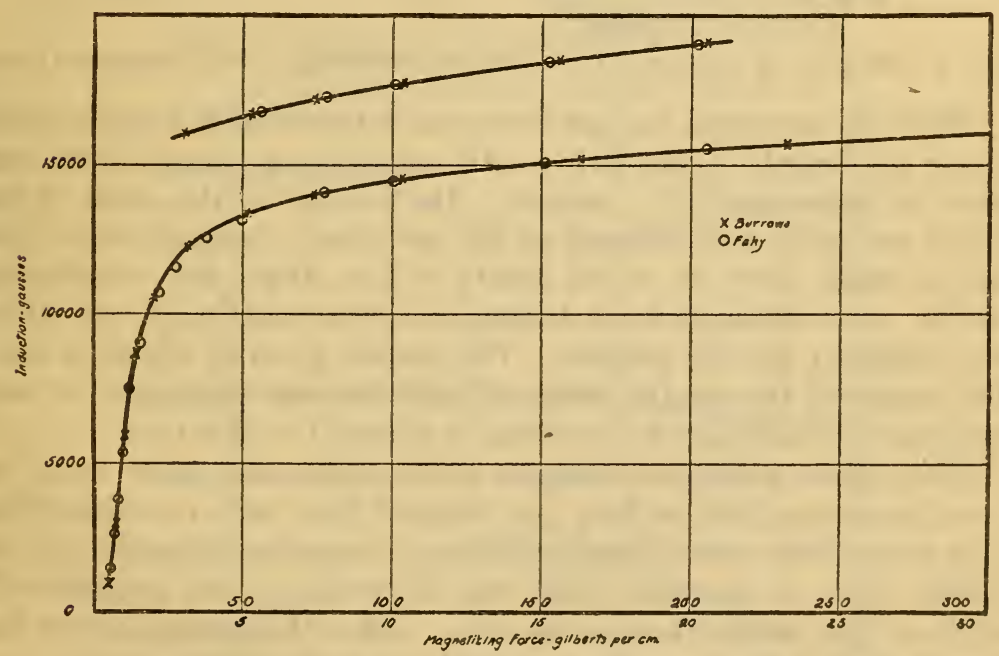

FIG. 4.-Normal induction showing good agreement between the Burrows permeameter and the Fahy Simplex permeameter

decided, therefore, to prepare samples made up of strips selected with reference to their uniformity and see whether the sign of the differences between values obtained by the two methods could be changed at will. 
A single sheet of No. 29 gauge high-silicon transformer steel was cut into longitudinal strips $4 \mathrm{~cm}$ wide, and these strips were tested for uniformity. The apparatus used for the uniformity test is shown diagrammatically in Figure 5. The strips were clamped in an iron yoke of adjustable length which afforded a return path for the magnetic flux. A magnetizing coil $10 \mathrm{~cm}$ long and having 10 layers of No. 17 silk enamel covered wire was mounted on rollers so that it could be moved along over the length of the specimen. A test coll of 100 turns and $1 \mathrm{~cm}$ in length was mounted within the magnetizing coil. This test coil, in series with the secondary of a standard mutual inductance (not shown), was connected to a ballistic galvanometer.

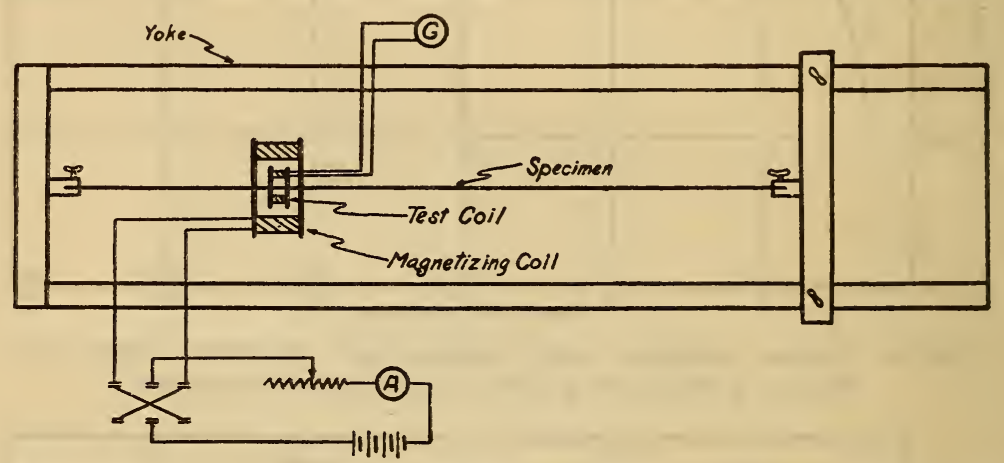

FIG. 5.-Diagram of apparatus for testing the uniformity of strips along their length

With this apparatus the induction was determined at 2-cm intervals along the length of the strips with magnetizing current held constant at approximately 1 ampere. On account of the effect of the joints and yoke near the end of the specimen, measurements could not be made over the whole length of the strips, but satisfactory results were obtained for a length of approximately $50 \mathrm{~cm}$, which was sufficient for the purpose. The graphs given in Figure 6 show the nature of the results obtained and illustrate the degree of nonuniformity which may be expected in material of this type.

From these strips two samples of 10 strips each were made up from pieces cut $25.4 \mathrm{~cm}$ long and selected from such portions of the long strips that one of the samples was magnetically harder at the middle than at the ends, while the other sample was magnetically softer at the middle than at the ends. After these two samples had been tested, a third sample was made up from strips selected from each of the two other samples so that the resultant would be as nearly uniform along its length as possible. The graphs for these three test specimens are given in Figure 7. 
Each of the three samples described above was tested in the Burrows permeameter and in the Fahy Simplex permeameter.

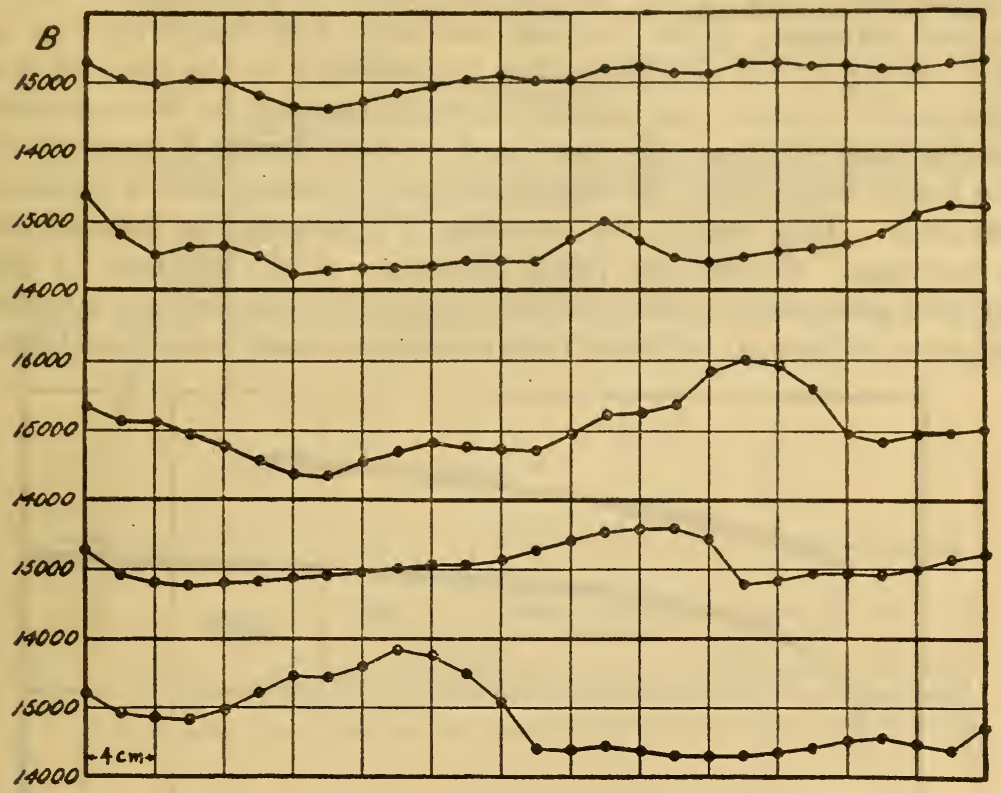

FIG. 6.-Typical results of uniformity tests of long strips

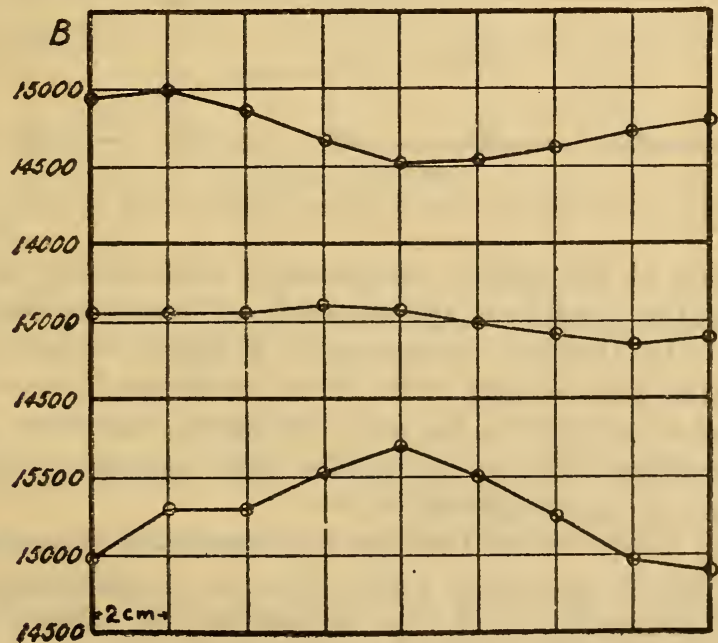

FIG. 7.-Magnetic uniformity of three test samples

The curves given in Figure 8 show graphically the difference between the results obtained with the two permeameters for the sample magnetically hard in the middle. The curve obtained with 
the Burrows apparatus is everywhere lower than that obtained with the Simplex. From previous experience it is known that for samples magnetically hard in the middle the Burrows permeameter gives normal induction curves that are too low. The reason for this is that, owing to the relatively high permeability at the ends of the specimen, less than the normal current is needed in the auxiliary magnetizing coils near the ends, and a larger current is required in the main magnetizing coil than would be necessary with a uniform specimen. This leads to the recording of a magnetizing force which is too high. We can not judge, therefore, of the accuracy of the Simplex permeameter from results obtained with nonuniform samples because the Burrows is known to be inaccurate under these conditions.

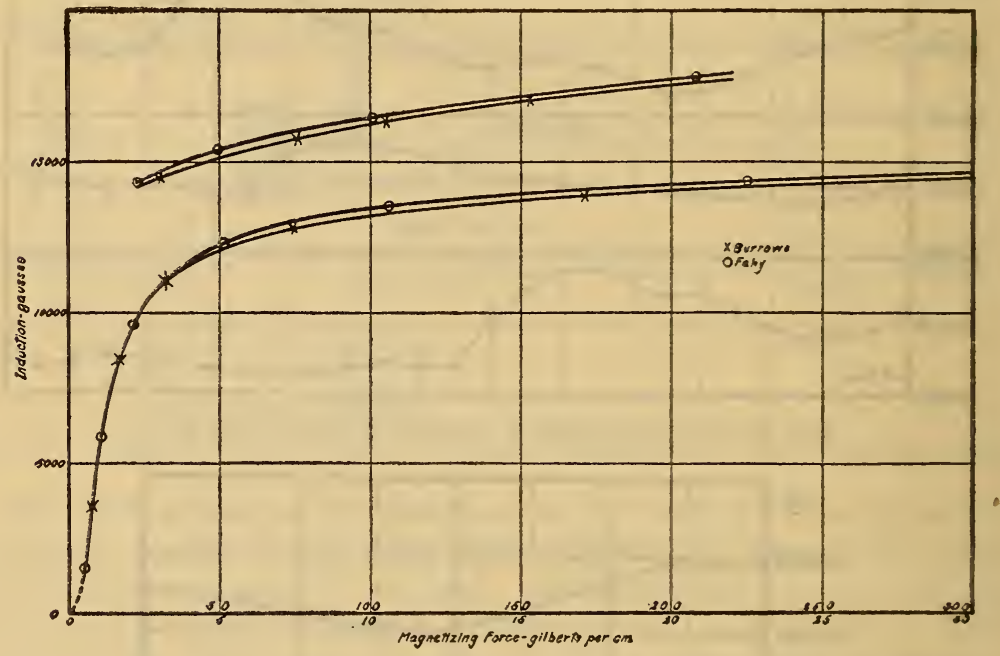

Fia. 8.-Normal induction curves for sample magnetically hard at the middle.

In the case of the sample magnetically softer in the middle than at the ends the conditions are reversed, as shown by the curves of Figure 9. The Burrows permeameter is known to give values of induction that are too high under these conditions because an excessive current is required in the end coils which, therefore, contribute some magnetizing force at the middle, thus making the actual force greater than the measured value.

From the results of the two test just described, it is seen that by proper choice of specimens with reference to their magnetic uniformity, it is possible to change the sign of the difference between the readings of the two permeameters at will.

The Burrows permeameter is an absolute instrument in the sense that its constants can be determined in terms of its dimensions. It 
is suitable, therefore, as a standardizing instrument provided it is used in connection with specimens having a satisfactory degree of magnetic uniformity along their length. The third sample tested was

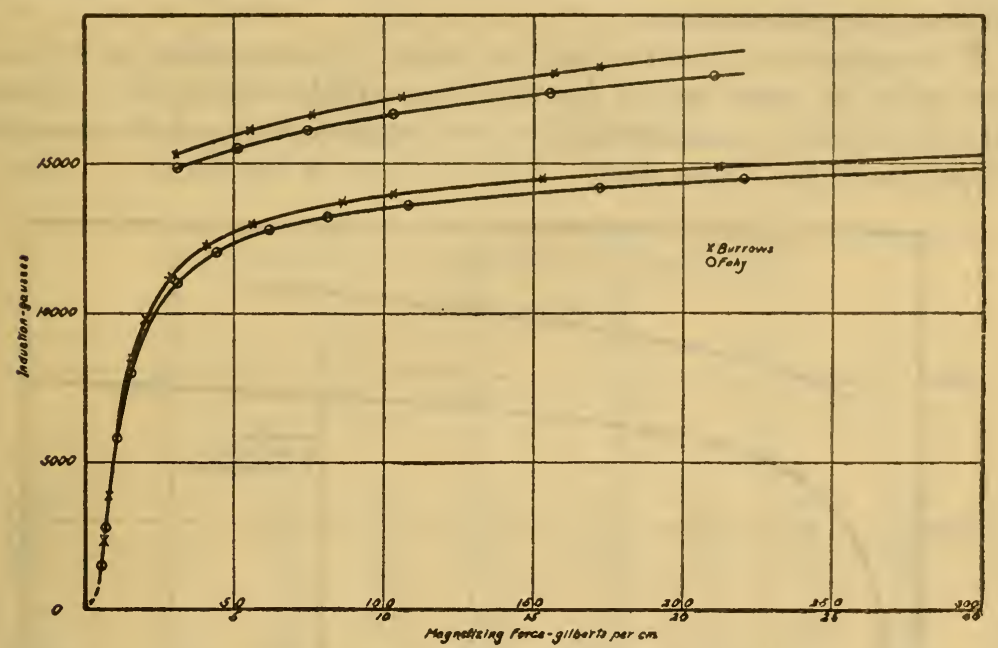

FIG. 9.-Normal induction curves for sample magnetically soft at the middle

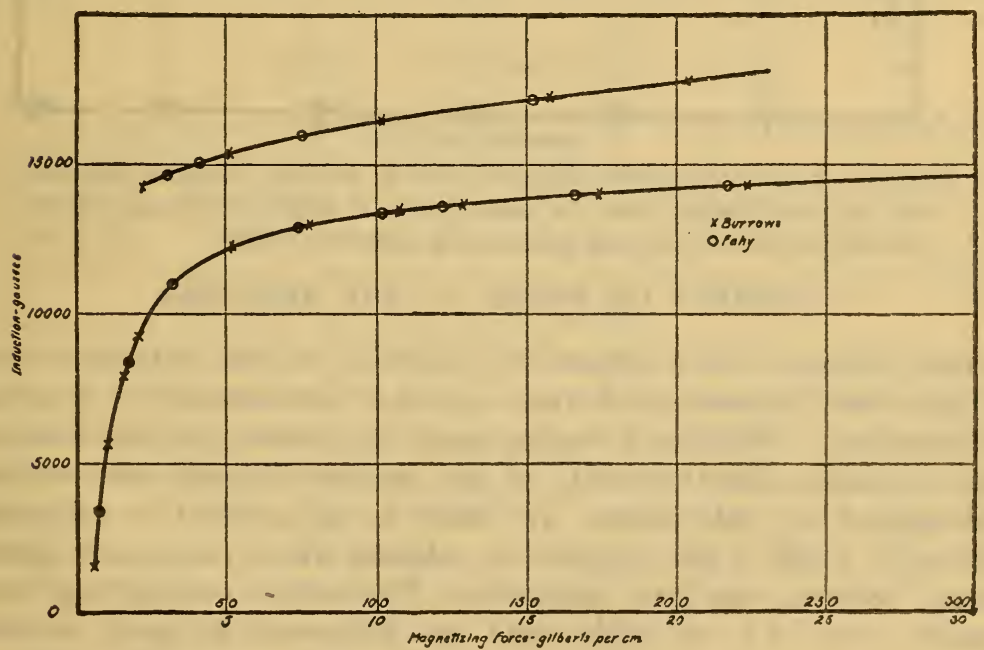

FIG. 10.-Normal induction curve of sample approximately uniform along its length

made up from strips chosen from the other two samples in such a way that the average permeability along the length of the composite sample would be as nearly constant as possible. Various combinations were tried and the best result obtained is represented in curve No. 3 of Figure 7. 
The results of the normal induction tests are shown in Figure 10. Although perfect agreement was not obtained it seems fair to assume that, with a uniform specimen, differences would be well within the limits of experimental error.

It is significant to note that the Simplex permeameter gave substantially the same results for all three samples which may, therefore, be logically considered to be fairly representative of the average properties of the whole sheet. This is shown in Figure 11.

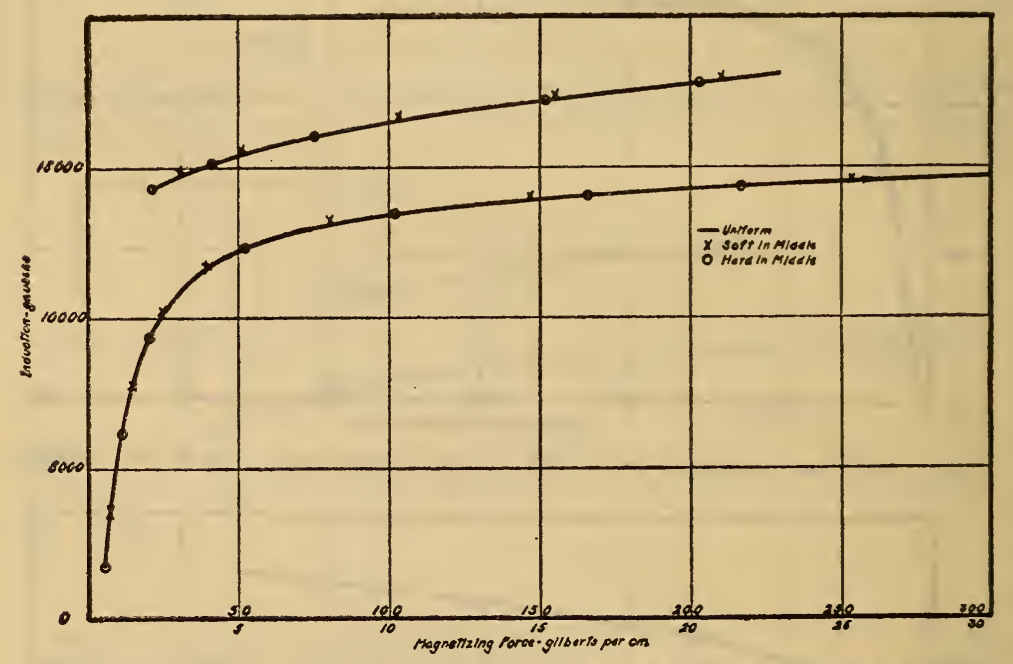

Fra. 11.-Results of normal induction tests in the Fahy Simplex permeameter of three samples from the same sheet, one uniform, one magnetically hard at the middle, and one magnetically soft at the middle

\section{EFFECT OF WIDTH OF THE SPECIMEN}

One influence which affects the results of normal induction tests of sheet steel is mechanical strain set up in the material by shearing or punching. ${ }^{3}$ This has a bearing upon the present problem because the minimum allowable width of test samples of sheet steel will be determined by this effect. In order to ascertain the minimum allowable width a test sample was selected which gave good agreement between the two methods. The strips making up this sample were $4.9 \mathrm{~cm}$ wide, and no difference as great as the allowable experimental error was found between the values obtained by the Burrows and Simplex permeameters. The width was then reduced by shearing to $3.9 \mathrm{~cm}$ and the sample retested. The results obtained with this width were identical with the original ones. Another centimeter was then taken off and another test made. In this case a slight difference from the first two tests was noted, 
but the two methods were still in agreement. When the strips were cut to a width of $1.9 \mathrm{~cm}$ there was a larger change noted, and the two methods no longer showed agreement. The numerical data are given in Table 1. From these data it was concluded that strips of sheet steel for normal induction tests should be not less than $3 \mathrm{~cm}$ wide. This is the width specified for the standurd core-loss test. Core-loss samples are, therefore, suitable also for normal induction tests.

TABLE 1.-Effect of width of strips on the magnetizing forces corresponding to given values of induction for various widths

[Width in centimeters]

\begin{tabular}{|c|c|c|c|c|c|c|c|c|}
\hline \multirow[t]{2}{*}{$-2-1=$} & \multicolumn{4}{|c|}{ Burrows } & \multicolumn{4}{|c|}{ Fahy } \\
\hline & 4.9 & 3.9 & 2.9 & 1.9 & 4.9 & 3.9 & 2.9 & 1.9 \\
\hline $\begin{array}{r}2,000 \\
4,000 \\
6,000 \\
8,000 \\
10,000\end{array}$ & $\begin{array}{l}0.61 \\
.84 \\
1.02 \\
1.31 \\
1.80\end{array}$ & $\begin{array}{l}0.61 \\
.84 \\
1.02 \\
1.31 \\
1.80\end{array}$ & $\begin{array}{l}0.68 \\
.81 \\
1.01 \\
1.30 \\
1.83\end{array}$ & $\begin{array}{l}0.65 \\
.87 \\
1.10 \\
1.40 \\
1.90\end{array}$ & $\begin{array}{l}0.61 \\
.84 \\
1.02 \\
1.31 \\
1.80\end{array}$ & $\begin{array}{l}0.61 \\
.84 \\
1.02 \\
1.31 \\
1.80\end{array}$ & $\begin{array}{l}0.68 \\
.81 \\
1.01 \\
1.30 \\
1.83\end{array}$ & $\begin{array}{l}0.63 \\
.86 \\
1.10 \\
1.40 \\
1.90\end{array}$ \\
\hline $\begin{array}{l}12,000 \\
14,000 \\
18,000 \\
19,000\end{array}$ & $\begin{array}{r}2.80 \\
7.10 \\
67.5 \\
127.0 \\
211.0\end{array}$ & $\begin{array}{r}2.80 \\
7.10 \\
67.5 \\
127.0 \\
211.0\end{array}$ & $\begin{array}{r}2.80 \\
7.05 \\
33.0 \\
123.0 \\
204.0\end{array}$ & $\begin{array}{r}2.88 \\
7.02 \\
28.4 \\
110.0 \\
181.0\end{array}$ & $\begin{array}{r}2.80 \\
7.10 \\
67.5 \\
127.0 \\
211.0\end{array}$ & $\begin{array}{r}2.80 \\
7.10 \\
67.5 \\
127.0 \\
211.0\end{array}$ & $\begin{array}{r}2.80 \\
7.05 \\
33.0 \\
123.0 \\
204.0\end{array}$ & $\begin{array}{r}3.03 \\
7.60 \\
31.8 \\
121.0 \\
198.0\end{array}$ \\
\hline
\end{tabular}

\section{EFFECT OF NUMBER OF STRIPS}

The iron blocks at the ends of the H-coil in the Simplex permeameter are in direct contact with only the outer strip of a sample and there is an appreciable magnetic reluctance between the inner and outer strip. For this reason it would appear that more than a certain maximum number of strips can not be taken for a sample without introducing too great an error in the results.

In order to test this point it was necessary to have samples sufficiently uniform along their length to avoid undue error due to lack of uniformity. It was also necessary that each strip have the requisite degree of uniformity because the test samples must contain various numbers of strips. This necessitated the testing of a considerable number of strips for uniformity. About 100 strips, $70 \mathrm{~cm}$ long, were examined before a sufficient number of $25 \mathrm{~cm}$ pieces of the requisite degree of uniformity were finally accumulated.

Forty strips were chosen on the basis of their uniformity and tested in four groups of 10 each. There was practically perfect agreement between the two permeameters for each of the four groups. Figure 12 is representative of the results obtained. With groups of 20 strips there were differences between the two methods in the lower part of the curve, but the curves came together for the higher inductions as shown in Figure 13. 
The maximum difference in magnetizing force for a given induction is of the order of 15 per cent, and occurs in the neighborhood of maximum permeability. The results with 30 and 40 strips showed correspondingly greater differences, and the curves did not come

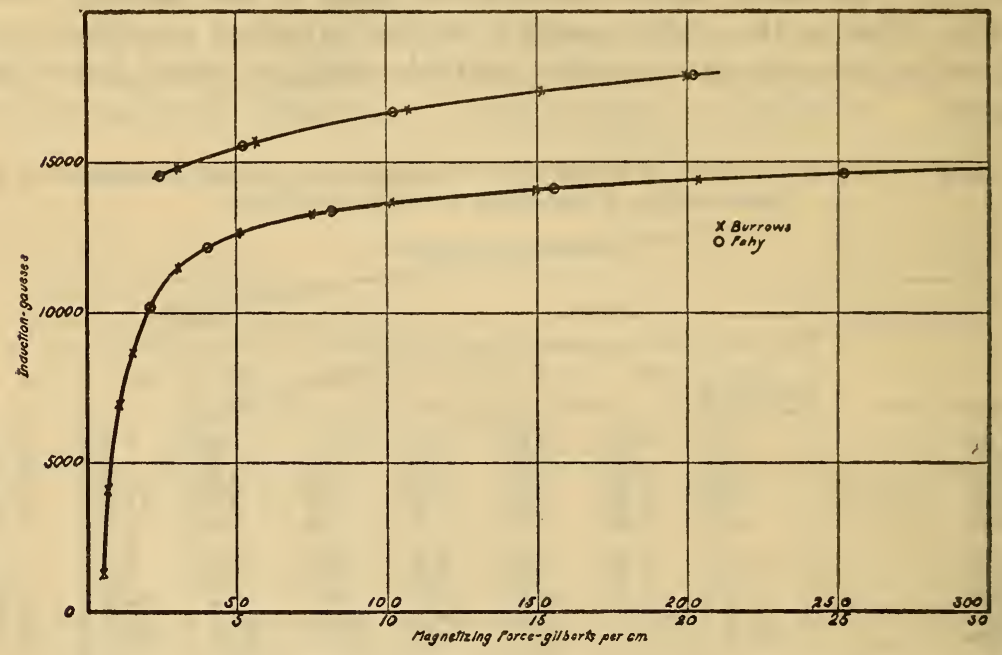

FIG. 12.-Normal induction curve of a uniform sample of 10 strips

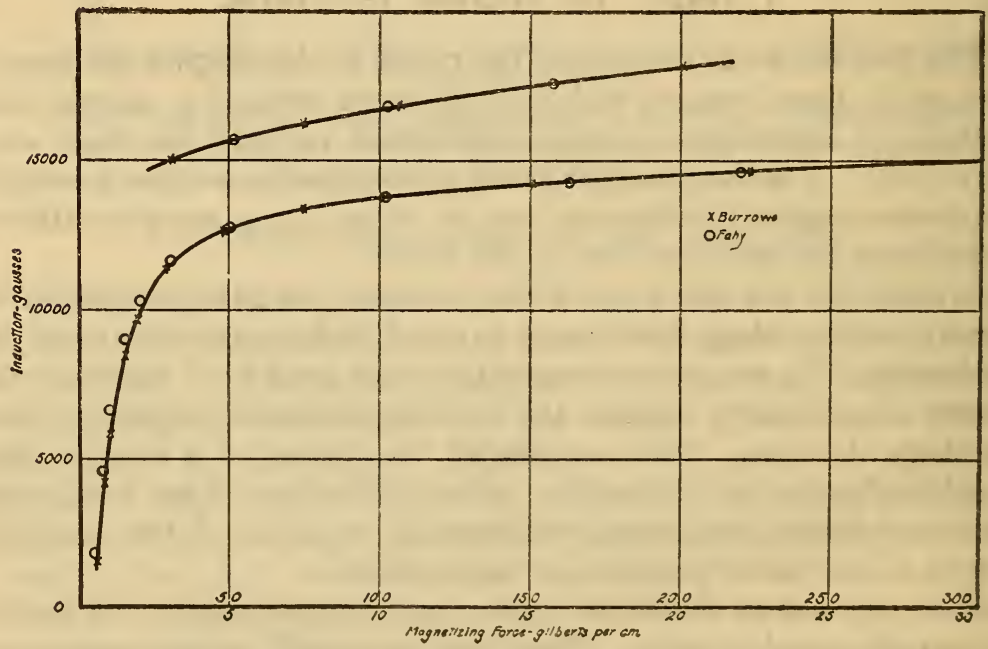

FIG. 13.-Normal induction curve of a uniform sample of 20 strips

together for the higher inductions. Figure 14 shows the results for 40 strips. In this case the difference near the region of maximum permeability is approximately 35 per cent. The differences for the 30strip sample were intermediate between those for 20 and 40 strips. 
From these results we may conclude that it is not safe to use more than about 15 strips in a sample and that it is better to use 10 . We are not justified, however, in saying that the observed differences represent the error in the Simplex permeameter without investigating the influence of the number of strips on the indications of the Burrows apparatus. This was done by plotting the average of the values obtained for the individual 10-strip groups and comparing with them the results for the corresponding numbers of strips tested together. This was done for each of the combinations of 20,30 , and 40 strip samples. It was found that the Burrows permeameter gave satisfactory values for 20 strips, but began to show deviations in the case of 30 strips in the lower part of the curve, the maximum being of the

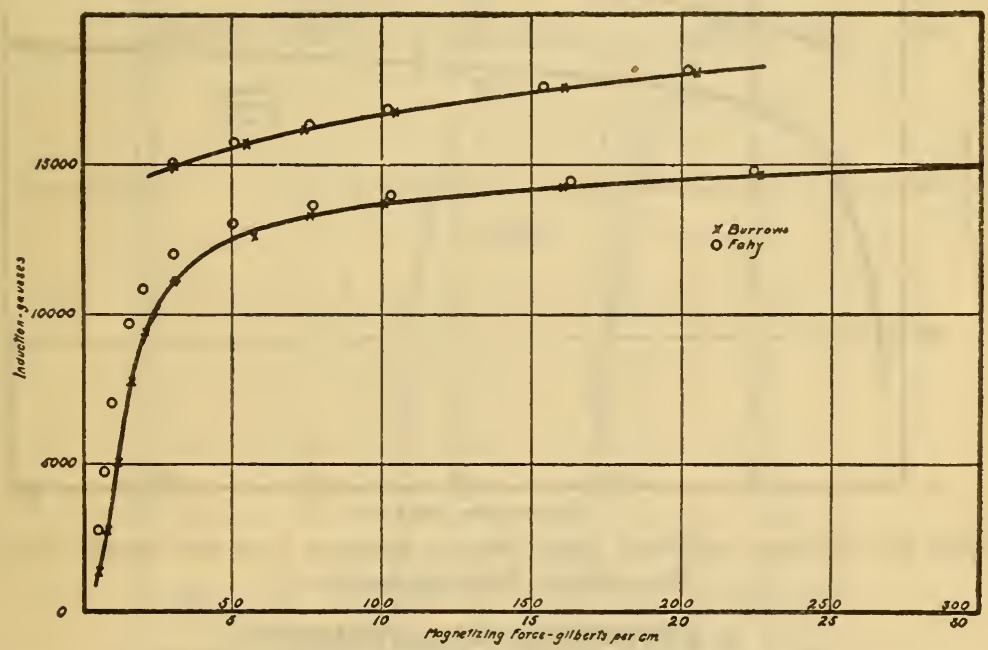

Fig. 14.-Normal induction curve of a uniform sample of 40 strips

order of 10 per cent. Figure 15 shows the results of the tests with 40 strips. These show that the Burrows permeameter gives too low values of induction in the lower part of the curve, but that the values are good in the upper part. The Simplex values are everywhere too high.

The question as to whether the difference observed with various numbers of strips in the sample is a function only of the number of strips or whether the thickness of the individual strips may have an influence was investigated by running a similar series of tests on specimens of No. 24 gauge material, which is approximately 0.635 $\mathrm{mm}$ thick, whereas the 29 gauge material is approximately $0.356 \mathrm{~mm}$ thick. The 24-gauge material was tested in groups of 6 strips chosen on the basis of uniformity as before. The 6-strip groups all gave good agreement between the two permeameters. With 12-strip 
samples small deviations were observed, but they were much less than those found with the 20-strip samples of the thinner material, which gave about the same total thickness of sample. With the 18strip samples the differences were of the same order as with the 20-strip samples of the 29-gauge material. From these results it was concluded that the predominating effect was due to the number of gaps between the $\mathrm{H}$ block and the pole piece in the Simplex permeameter, and that for any gauge of material ordinarily used in electrical apparatus a sample of 10 strips will give the best results.

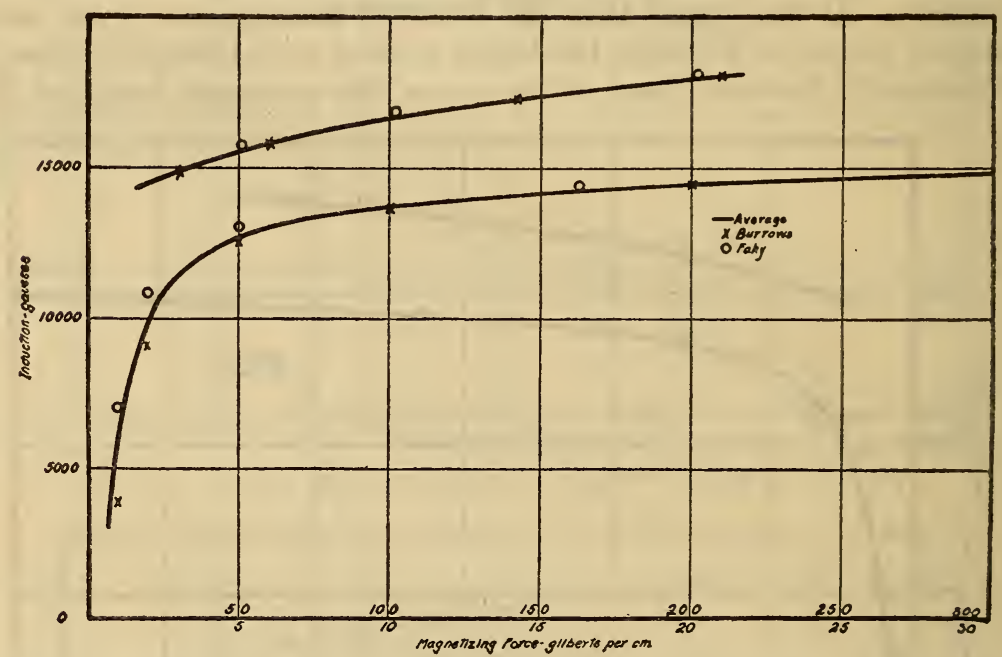

FIG. 15.-Normal induction curve showing deviation from the average of the Burrows and Fahy permeameters

\section{HYSTERESIS MEASUREMENTS}

Hysteresis measurements are not very frequently made on the type of material under discussion, but, for the sake of completeness, hysteresis measurements were made on the three samples of No. 29 gauge material used for investigating the effect of uniformity. The residual induction and coercive force were obtained from a maximum induction of 10,000 gausses and practically the same order of agreement was found in all cases. The Simplex gives a value of residual induction lower by about 1 per cent than the Burrows while the coercive force is approximately 10 per cent higher. Figure 16 shows the hysteresis loops for the uniform sample. These differences, while fairly large on a percentage basis, are relatively insignificant practically. Moreover, the accuracy of the Burrows permeameter for hysteresis values on material of this type has not been determined with any certainty. Probably the best results in this regard are those of Spooner ${ }^{4}$ who

- Spooner, Elec. J., 21, p. 353; 1921. 
finds that, compared with an elongated ring or link specimen tested by the regular Rowland ring method, the Burrows permeameter gives high values for residual induction and low values for coercive force. It appears to be fairly safe to assume, therefore, that for sheet material, if the conditions are right for obtaining satisfactory accuracy in normal induction measurements, the results of hysteresis tests will also be satisfactory.

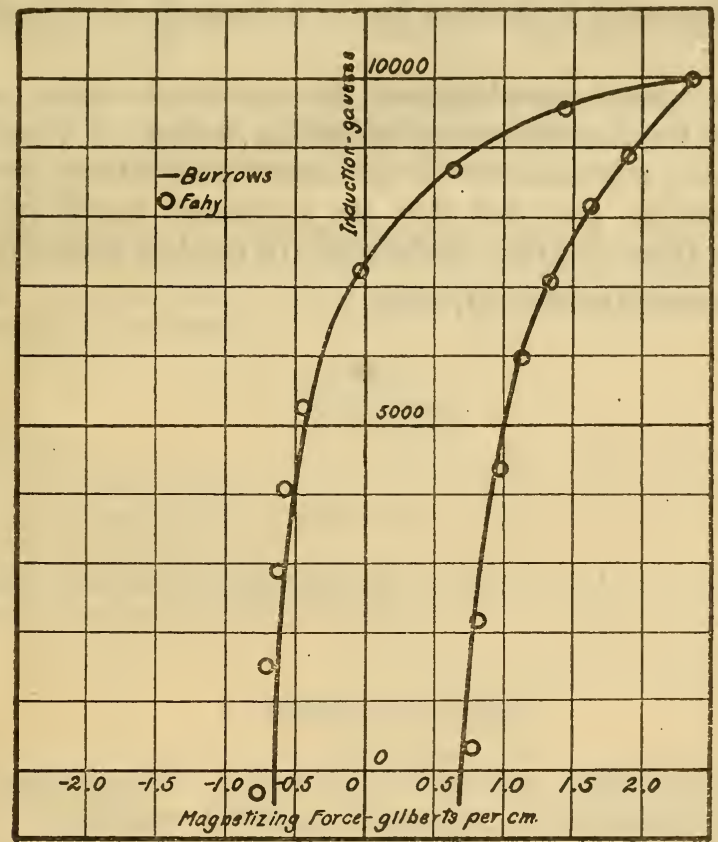

Fig. 16.-Comparison of results of hysteresis tests by the Burrows and Fahy permeameters

\section{CONCLUSIONS}

From the experiments described in the foregoing we have concluded that differences between the results of normal induction tests on sheet steel by the Burrows permeameter and the Fahy Simplex permeameter are to be attributed to the character of the specimen rather than to errors inherent in either method. The greatest source of discrepancy is lack of magnetic uniformity along the length of the specimen. The Burrows permeameter is more sensitive to this condition than the Simplex. An excessive number of strips in the specimen causes bad flux distribution which leads to errors in the results. The Simplex permeameter is more sensitive to this factor than the Burrows. The width of the strips used in the sample also plays a part 
in the results. They should not be less than $3 \mathrm{~cm}$ wide if the effect of punching or shearing strains is to be avoided.

The degree of nonuniformity in a test sample of sheet steel made up in the usual way will generally not be as great as that of the samples used for testing this point in the present investigation, so it is probable that the results of tests with the Burrows permeameter will ordinarily be satisfactory. On the other hand, there will always be uncertainty as to the accuracy obtained by this method unless the uniformity of the specimen is checked and it is generally not convenient to do this.

From the above considerations the conclusion seems to be warranted that for routine normal-induction testing of sheet steel the Fahy Simplex permeameter is the most satisfactory apparatus at present available, provided that the specimens tested are made up of not more than 15 strips (preferably 10) not less than $3 \mathrm{~cm}$ wide.

Washington, October 21, 1926. 